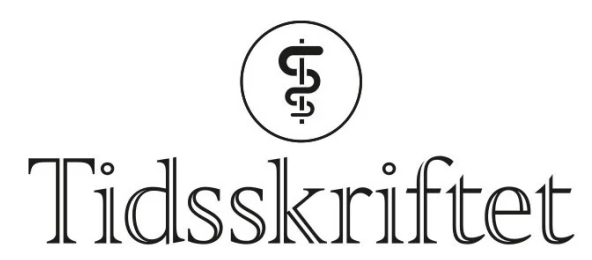

DEN NORSKE LEGEFORENING

\title{
EEG ved koma
}

\author{
OVERSIKTSARTIKKEL
}

\section{JOHN A. WILSON}

John Wilson (f. 1949) er spesialist i nevrologi og klinisk nevrofysiologi med spesiell interesse for nevrofysiologiske mekanismer og EEG ved søvnsykdommer, epilepsi og koma. Han er nå overlege ved Avdeling for kompleks epilepsi, Oslo universitetssykehus.

Forfatter har fylt ut ICMJE-skjemaet og oppgir ingen interessekonflikter.

Email: johwil@ous-hf.no

Seksjon for klinisk nevrofysiologi

\section{HELGE J. NORDAL}

Helge J. Nordal (f. 1944) er spesialist i nevrologi og pensjonert overlege ved Nevrologisk avdeling, Oslo universitetssykehus og professor ved Universitetet i Oslo.

Forfatter har fylt ut ICMJE-skjemaet og oppgir følgende interessekonflikter: Han har hatt oppdrag for advokater, forsikringsselskaper og domstoler i personskadeerstatningssaker og mottatt

forelesningshonorar for etterutdanningsskurs både for jurister og for leger.

Nevrologisk avdeling

Oslo universitetssykehus

\section{BAKGRUNN}

Koma er en dynamisk tilstand som kan ha ulike årsaker. Viktige forandringer kan skje på kort tid, ofte med konsekvenser for behandlingen. Formålet med denne artikkelen er å gi en kortfattet oversikt over EEG-mønstre ved koma av ulike årsaker og hvordan EEG kan bidra ved vurdering av prognosen ved koma.

\section{KUNNSKAPSGRUNNLAG}

Artikkelen er basert på flerårig klinisk og forskningsmessig erfaring med EEG ved komatilstander. Egen opparbeidet litteraturdatabase er komplettert med søk i PubMed etter relevante artikler.

\section{RESULTATER}

EEG viser umiddelbare forandringer ved koma og kan tidlig gi informasjon om årsak og prognose. Det er det eneste diagnostiske redskapet for å påvise ikke-konvulsiv epileptisk status. «Locked-in syndrome» kan overses uten EEG. Gjentatte EEG-registreringer øker den diagnostiske sikkerheten og gir mulighet til å følge utviklingen av koma.

\section{FORTOLKNING}

EEG avspeiler fortløpende hjernens funksjon og har derfor en sentral plass i utredning og behandling av koma. 

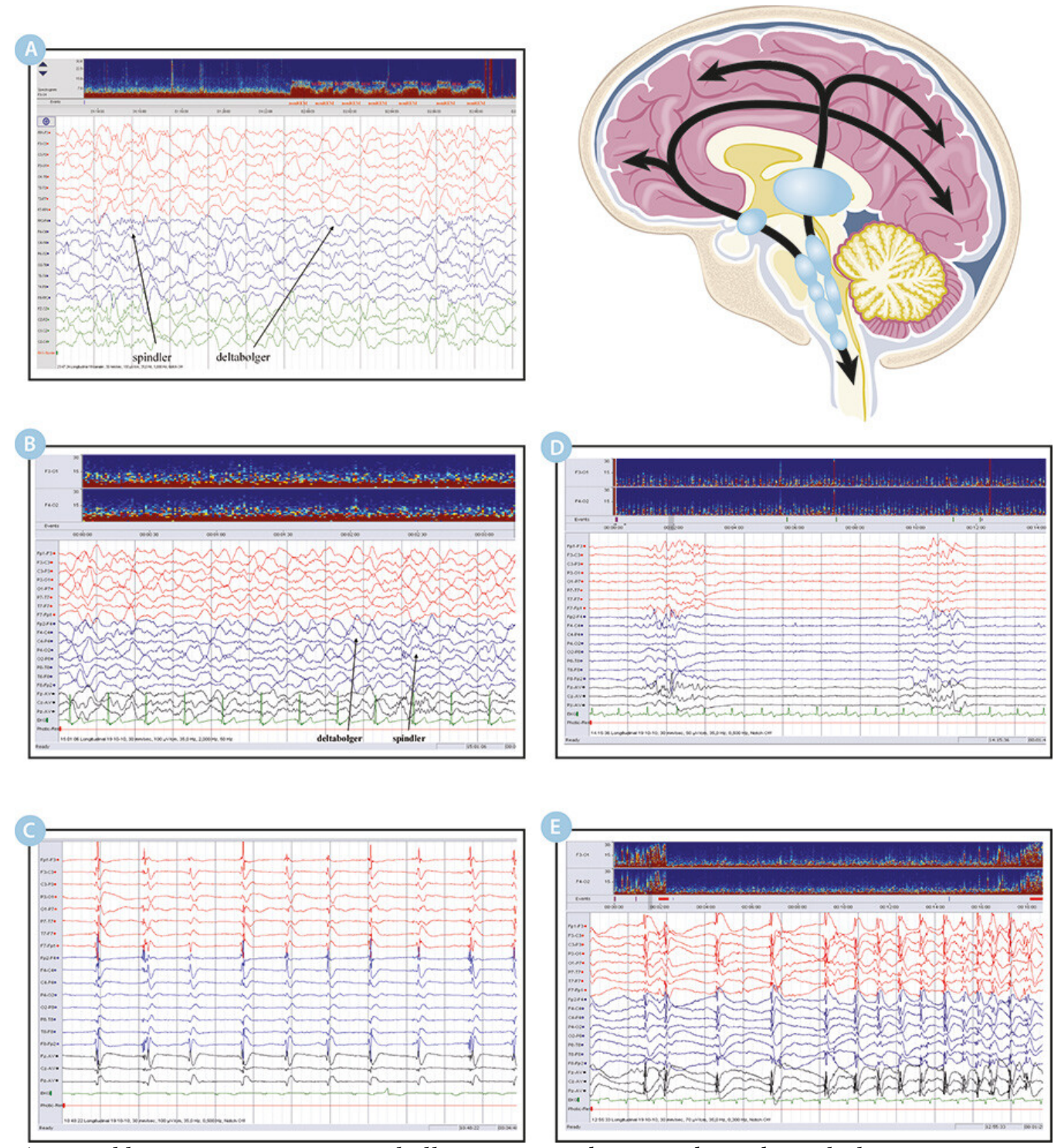

Øverst til høyre vises en anatomisk illustrasjon av det ascenderende retikulære aktiveringssystemet som består av to deler: det ventrale som går gjennom hypothalamus, og det dorsale som går gjennom thalamus. Det er fem EEG-utskrifter: A) EEG ved normal søvn. Det øverste blå panelet viser frekvensspektrogram (dominerende frekvenser langs Yaksen og tiden langs X-aksen) gjennom registreringen, i dette tilfellet gjennom hele døgnet. Siste halvdel viser soveperioden, med sju REM/NREM-sykluser. EEG-sekvensen viser 12 sekunder NREM-søvn, med spindler og deltabølger. Rødt er fra venstre side og blått fra høyre side av hodet. B) EEG fra pasient med akutt demyeliniserende encefalomyelitt i øvre hjernestamme. EEG viser vedvarende dyp søvn med bevart kortikotalamisk interaksjon (sammenlikn med utskrift A), men uten reaktivitet. Det ses ingen veksling mellom NREM og REM-søvn (se øverste panel med spektrogram i 3,5 timer) fordi REM-NREM-vekslingen reguleres i øvre hjernestamme. C) EEG med status myoclonicus fra pasient som var blitt resuscitert etter hjertestans. D) EEG fra en annen pasient som var blitt resuscitert etter hjertestans. EEG viser lavspenning med periodiske utbrudd (burst-suppression). E) EEG fra en pasient som var blitt resuscitert etter hjertestans. Her vises periodisk aktivitet og ikkekonvulsiv status epilepticus. Spektrogrammet viser en periode på 18 minutter med periodisk aktivitet, forutgått og etterfulgt av to kortere sekvenser kontinuerlig epileptisk aktivitet (markert med rødt). Illustrasjon @ Illumedic

«Koma» stammer fra gresk og betyr dyp søvn. Betegnelsen forekommer først hos Hippokrates (ca. 46o-370 f.Kr.) og siden hos Galen (129-199 e.Kr.) (1). Betegnelsen dukker opp igjen hos Thomas Willis (1621-75). Han klassifiserte tilstanden i letargi (gr. lethe $=$ glemsomhet) og argos (gr. = doven) med årsak i cortex og koma med årsak under cortex (altså subkortikalt) (11). Med von Economos (1876-1931) påvisning av lesjoner i 
hypothalamus hos pasienter som døde etter encephalitis lethargica (므), og den senere påvisning av det ascenderende retikulære aktiveringssystemet (3), ble det klart at koma kunne forårsakes av affeksjon i alle disse strukturene (se illustrasjon).

Kortikale skader vil kunne påvirke informasjonsintegrering, med forvirring, hallusinasjoner eller hukommelsesproblemer som resultat, uten at våkenhetsgraden behøver å være påvirket. En diffus kortikal affeksjon vil imidlertid kunne forårsake bevissthetsreduksjon, avhengig av mengden av affisert cortex. En skade som påvirker aktiveringssystemene i hjernestamme, midthjerne eller thalamus kan være liten, men forårsake dyp koma.

I dag menes med koma en patologisk tilstand med opphevet bevissthet, uten respons på ytre eller indre stimuli (4.). Tilstanden kan vare fra timer til uker og utvikle seg enten til oppvåkning med eller uten sekveler, til død eller til en varig tilstand der pasienten kan være «våken», men uten (eller med minimalt) bevissthetsinnhold, såkalt kronisk vegeterende tilstand (4).

En oversikt over klinisk diagnose, gradering og årsaker til koma sprenger rammene for denne oversikten. For dette anbefaler vi en meget god oversikt ved Young (5). I denne artikkelen søker vi å gi en prinsipiell forståelse av elektroencefalografi (EEG), med en skisse av den grunnleggende fysiologien og noen enkle patofysiologiske betraktninger. Videre vil vi presentere en oversikt over EEG-funn med kjent prognostisk verdi ved komatilstander samt en oversikt over funn som har behandlingsmessig konsekvens.

\section{Kunnskapsgrunnlag}

Oversikten baserer seg på forfatternes omfattende kliniske og forskningsmessige erfaring med EEG hos komatøse pasienter samt et skjønnsomt utvalg av relevante artikler om EEG ved koma. Artiklene er valgt ut fra egen opparbeidet litteraturdatabase og komplettert med søk i PubMed etter relevante artikler. Søket ble avsluttet oktober 2011.

\section{Hva måler et skalp-EEG?}

EEG som registreres med elektroder festet på hodehuden kalles et skalp-EEG.

Hjernebarkens eksitatoriske pyramideceller er organisert i funksjonelle kolonner som står vinkelrett på overflaten. Den elektriske aktiviteten i disse genererer feltpotensialer i samspill med inhibitoriske internevroner. Potensialene er et uttrykk for summen av den synaptiske aktiviteten (므). Inhibisjon og eksitasjon i nevronene og de nevronale nettverkene gjør at feltpotensialene synkroniserer og oscillerer i ulike frekvenser og spenninger (7.). Dess færre nevroner som oscillerer i små nettverk, jo raskere frekvens og mindre spenning. Det er denne aktiviteten som måles ved et EEG. Noe av aktiviteten kan registreres med elektroder festet på skalpen, men for å registrere de raskeste og minste oscilleringene behøves det intrakraniale elektroder.

Interaksjon mellom cortex, thalamus, hypothalamus og hjernestammen genererer under søvn langsomme oscilleringer som kan involvere samtlige nevroner i store nettverk (ㅁ)-(10). Dette har relevans for komadiagnostikken.

I et skalp-EEG registrert i avslappet, våken tilstand og med lukkede øyne dominerer aktivitet med frekvens 8-13 per sekund (alfaaktivitet) over de bakre hodeområdene. Over de fremre hodeområdene dominerer rask aktivitet med frekvens 13-30 per sekund med lav spenning (betaaktivitet). Under lett søvn dominerer langsommere aktivitet på 4-7 per sekund (tetaaktivitet). Under dypere søvn (non rapid eye movement sleep, NREM) dominerer spolformige sekvenser på 10-16 per sekund (sigma- eller spindelaktivitet) og 
langsom aktivitet på 1-4 per sekund (deltaaktivitet) med høyere spenning. Begge disse moduleres av langsom bakgrunnsoscillering på o,2-1 per sekund. NREM-søvn veksler med REM-søvn i ca. 70-8o minutters perioder (illustrasjon, EEG-uskrift A).

\section{Kortikale forstyrrelser}

Diffuse kortikale forstyrrelser kan redusere den synaptiske aktiviteten, skade nettverk og forstyrre forholdet mellom eksitasjon og inhibisjon. Dette fører oftest til at innslaget av langsomme bølger i EEG blir større enn normalt. Når eksitatoriske mekanismer dominerer, kan det imidlertid oppstå avvikende rytmer, som periodiske eller vedvarende såkalte trifasiske bølger, eller klar epileptisk aktivitet. Uttalt kortikal hypereksitabilitet eller disinhibisjon kan i EEG vise seg som generalisert epileptisk aktivitet og kan noen ganger være en selvstendig årsak til redusert bevissthet. Slike EEG-forandringer ses hovedsakelig ved hypoksiske, metabolske eller toksiske årsaker til koma. Det kan også ses ved ulike progredierende encefalopatier som ender i koma, som for eksempel Creutzfeldt-jakobs $\operatorname{sykdom}(\underline{11}, \underline{12})$.

\section{Subkortikal hvit substans}

Skader i subkortikal hvit substans gir funksjonsforstyrrelser i cortex pga. deafferentering av de berørte kortikale områdene. Disse vil da tendere til patologisk hypersynkronisering (9). I EEG ses dette som intermitterende langsomme bølger av relativ høy amplitude, i frekvenser på 3-7 per sekund. I grove trekk er bølgene langsommere, mer høyspente og over et større område desto dypere lesjonen sitter. Hvis skaden også berører cortex kan rytmene bli epileptiforme. Slike EEG-forandringer kan ses etter kontusjoner, intracerebrale blødninger, infarkter, svulster og encefalitter. Graden av bevissthetsendring er avhengig både av hvor stor mengde av cortex og av hvilken region som er deafferentert (13). Ekspanderende intrakraniale prosesser, som svulster, blødninger eller abscesser, kan også redusere bevisstheten ved påvirkning av aktiveringssystemene i øvre hjernestamme og midthjerne (14.). Gjentatte EEG-målinger kan avsløre en slik utvikling.

\section{Thalamus, hypothalamus, mesencephalon og hjernestamme}

Det kortikotalamiske systemet inngår i en kontinuerlig og døgnvarierende interaksjon med mesencefale og hypotalamiske søvnreguleringssystemer, med det frontobasale aktiveringssystemet og med det retikulære aktiveringssystemet (15). Den kortikale aktiviteten er i konstant interaksjon med thalamus (므). Dette er synlig i EEG som karakteristiske mønstre under søvn. Mønstrene kan gi en indikasjon på hvilke systemer som er affisert.

Omfattende skader i øvre hjernestamme kan i EEG vise seg nærmest som en dyp fysiologisk søvn. Ved slike skader er imidlertid hele det kortikotalamiske systemet og det frontobasale vekkesystemet i hypothalamus deafferentert. Søvnfysiologisk kortikotalamisk interaksjon kan imidlertid være bevart. En slik koma skiller seg i EEG ikke fra fysiologisk søvn, men pasienten er ikke vekkbar (illustrasjon, EEG-utskrift B).

Noen ganger kan det dorsale og det ventrale aktiveringssystemet være affisert i ulik grad. Dette manifesterer seg i EEG med ulik reaktivitet på sensoriske stimuli. Disse kan enten gi en generell aktivering med raskere bølger eller en "paradoksal» aktivering med innslag av langsomme bølger. Slik aktivitet er ofte rytmisk, høyspent og paroksystisk. Fullstendig manglende aktiveringseffekt tyder på en mer omfattende affeksjon. Dette er vanligvis et dårlig tegn. 
Skade i pons vil ofte påvirke bevisstheten. Hvis det pontine tegmentum også er affisert, kan EEG vise en vedvarende bilateral rytmisk aktivitet. Pasienten er da i såkalt alphakoma, thetakoma eller alpha-thetakoma, avhengig av den dominerende rytmefrekvensen. Slik aktivitet dominerer over de bakre hodeområder. Denne type «rytmisk koma» kan også ses etter hypoksisk skade. Alpha- og theta-rytmene dominerer da over de fremre områder, og er ikke reaktive på sensoriske stimuli (17, 18).

"LOCKED-IN»-SYNDROM

Hvis skaden begrenses til ventrale pons og ikke involverer det pontine tegmentum, kan pasienten være ved full bevissthet, men deefferentert. Pasienten er da mutistisk og nesten komplett paralysert. Vertikale øyebevegelser og blunking er imidlertid bevart og blir den eneste kommunikasjonsveien $(\underline{19}, \underline{20})$. For pasienten er dette en svært skremmende tilstand. EEG viser i slike tilfeller en normal og reaktiv alfaaktivitet når pasienten er våken. EEG-messig er også søvnfysiologien bevart. Omfattende polyradikulitt (Guillain-Barrés syndrom) og myopati/nevropati ved kritisk sykdom (critical illness myopathy/neuropathy) kan også forårsake en liknende tilstand (21).

Det er klinisk svært viktig at «locked-in»-syndrom ikke forveksles med alfakoma. EEG er, slik det fremgår, essensielt for å skille disse to tilstandene.

\section{Iskemisk koma}

Ved iskemisk koma kan det ses et vidt spekter av forandringer i EEG $(\underline{\mathbf{2 2}}, \mathbf{2} 3)$. Hjernens kortikale pyramidecellesystem er mest sårbart for iskemi, men det kan være store individuelle variasjoner. Hypoksien kan ha utviklet seg raskt, som ved hjertestans, eller langsommere, som ved respirasjonsstans med initialt bevart cerebral perfusjon. Ulike medikamenter kan også påvirke hjernens sårbarhet for iskemi. Kroppstemperatur kan være en viktig faktor, slik som ved drukningsulykker eller annen form for nedkjøling. Noen områder av hjernen kan også være mer utsatt pga. arteriosklerose med nedsatt perfusjon.

I EEG kan dette resultere i forskjellige grader av diffus kortikal funksjonsnedsettelse uten eksitatoriske elementer. Hypereksitabilitet eller disinhibisjon er imidlertid også vanlig. Dette kan gi epileptiforme forandringer av forskjellig type og omfang, slik som tilspissede trifasiske bølger eller periodisk eller vedvarende epileptisk aktivitet (24).). Generalisert epileptisk aktivitet kan arte seg som et såkalt status myoclonicus-mønster på EEG (nå brukes ofte benevnelsen "generaliserte periodiske epileptforme utbrudd»)(illustrasjon, EEG-utskrift C). En slik tilstand gir vedvarende myoklonier som ikke responderer på antiepileptika. Tilstanden kan kun bringes til opphør ved så dyp sedering at EEG blir «flatt», uten at prognosen derved bedres. Man må være oppmerksom på at EEG kan fremvise slike forandringer uten at pasienten har myoklonier. Motsatt kan pasienten ha myoklonier uten at slike forandringer vises på EEG. Det antas at slike varianter er utrykk for at kortikale lag er affisert ulikt (25).

"BURST-SUPPRESSION"

Ved svært omfattende anoksisk skade vil det være tegn til kombinert metabolsk svikt og kortikal disinhibisjon (26). Dette kalles «burst-suppression»-mønster. Når dette skyldes anoksisk skade, er det vanligvis et terminalt EEG-fenomen (illustrasjon, EEG-utskrift D). Opphør av kortikal synaptisk aktivitet medfører et «flatt» EEG. Man må imidlertid være oppmerksom på at dyp sedering og dyp hypotermi - særlig i kombinasjon - også kan forårsake både «burst-suppression» og «flatt» EEG.

GJENTATT EEG ER NYTTIG

Når koma varer over timer og dager, skjer det en metabolsk utvikling med tilsvarende endringer i EEG-bildet. Det kan være nyttig med gjentatte EEG-undersøkelser, dels for å vurdere prognose, dels fordi det underveis kan oppstå behandlingstrengende epileptisk aktivitet.

\section{Ikke-konvulsiv status epilepticus}


Ikke-konvulsiv status epilepticus foreligger når EEG viser vedvarende epileptisk aktivitet uten at den komatøse pasienten viser motoriske symptomer. Diagnosen brukes når fenomenet ses hos en pasient med epilepsi som har gått inn i en langvarig tilstand med nedsatt bevissthet eller forvirring. En sjelden gang kan pasienten være i koma utelukkende pga. dette. Tilstanden kan kun diagnostiseres med EEG.

Også hos pasienter som er i koma av annen årsak enn kjent epilepsi kan diagnosen brukes. Det er viktig å skille dette fra ikke-konvulsiv status epilepticus hos pasienter med epilepsi (27.)-(30).

Ikke-konvulsiv status epilepticus ved koma kan oppstå underveis i sykdomsforløpet og kan bidra til forverring av prognosen. En slik tilstand bør føre til behandlingsforsøk med et ikke-sederende antiepileptisk medikament. I beste fall kan pasienten våkne til, samtidig som EEG bedres. Dessverre er EEG-funnet ofte et bifenomen til komaårsaken. Ofte er det da et tegn på alvorlig skade med svært dårlig prognose.

Ikke-konvulsiv status epilepticus kan gi ulike EEG-mønstre, avhengig av den underliggende årsaken. En hypoksisk skade vil oftest gi generaliserte EEG-forandringer. Encefalitt, hjernekontusjon eller cerebralt infarkt vil gi fokale eller lateraliserte epileptiske EEGforandringer. Periodisk tilspisset aktivitet oppfattes av enkelte som interiktal epileptisk aktivitet, siden den iblant viser overgang til ikke-konvulsiv status epilepticus (illustrasjon, EEG-utskrift E), mens andre anser det som et iktalt fenomen (31,32), som kan bedre prognosen dersom det behandles (33). Når man ser slik periodisk aktivitet, bør man uansett være på vakt mot utvikling av ikke-konvulsiv status epilepticus. Det hender at tilstanden må behandles med dyp sedering monitorert med EEG helt til «burst-suppression»-mønster viser $\operatorname{seg}(33)$.

Risikoen for utvikling av ikke-konvulsiv status epilepticus er relativt høy ved koma av alle årsaker (34.). Dette understreker betydningen av EEG hos komatøse pasienter.

\section{Hjernedød og kronisk vegeterende tilstand}

I Norge brukes ikke EEG til å diagnostisere hjernedød for å avslutte behandling eller for å tilrettelegge for organdonasjon. Ofte er EEG likevel tatt i en slik forbindelse, og det omtales derfor kort her. Total kortikal ødeleggelse viser seg ved fravær av aktivitet i skalp-EEG.

Ved EEG-taking skal hypotermi under $32{ }^{\circ} \mathrm{C}$, sirkulatorisk sjokk og sedering være utelukket. Årsaken skal være kjent, og kliniske tegn til hjernedød skal ha vært til stede i 12 timer, men dette kan reduseres til seks timer hvis det er avklart at årsaken er irreversibel (35,3므).

Pasienter i kronisk vegeterende tilstand, dvs. uten bevissthetsinnhold, men med bevarte hjernestammestrukturer som opprettholder autonome funksjoner, kan noen ganger være uten synlig kortikal aktivitet i skalp-EEG. De fleste fremviser imidlertid EEG-aktivitet som er svært lavspent, langsom, uregelmessig og uten reaktivitet på sensoriske stimuli. Det ses heller ingen døgnvariasjon i EEG, selv om pasienten klinisk fremviser døgnsykluser av søvn og våkenhet.

\section{Psykogent eller simulert koma}

En sjelden gang står man overfor en tilsynelatende bevisstløs pasient med ellers normal klinisk nevrologisk status. Ved tvil om pasienten er i koma, kan EEG avsløre normal våkenhet. Dermed kan annen ressurskrevende diagnostikk unngås.

\section{Prognostiske vurderinger}


Stilt overfor en komatøs pasient er det viktig å kunne beslutte hvorvidt det skal startes, eller fortsettes, maksimal og ressurskrevende behandling (37.). EEG har en plass i disse vurderingene, ikke minst fordi det er lite ressurskrevende, kan gjentas ubegrenset og reflekterer hjernens funksjonsendringer.

Hvis prognosen skal vurderes, må årsaken til koma være avklart og komaen skal ha vart i minst 24 timer. Pasienten skal ikke være sedert, hypoterm under $32{ }^{\circ} \mathrm{C}$ eller i sirkulatorisk sjokk. Kun EEG tatt ved koma etter hjertestans har tilnærmet entydig prognostisk verdi (3으, 39.). Ved andre årsaker, spesielt ved traumatisk skade, bør man vise tilbakeholdenhet $i$ prognosesetting på bakgrunn av EEG alene. Med dette forbeholdet kan følgende prognostiske faktorer allikevel postuleres $(3 \underline{8}, 39$ ):

- «Burst-suppression» og status myoclonicus tilsier svært dårlig overlevelsesprognose, men det er sett tilfeller av relativt god restitusjon etter status myoclonicus.

- Ved ikke-reaktiv rytmisk koma (alfa eller teta) er det ytterst sjelden restitusjon til selvhjulpen tilstand, og det ender som regel med død eller kronisk vegeterende tilstand.

- Vedvarende generalisert lavspent og langsom aktivitet som ikke er reaktiv på sensoriske stimuli, innebærer høy dødelighet eller overlevelse med svært dårlig nevrologisk restitusjon.

- Periodisk aktivitet i form av vedvarende innslag av enkeltbølger eller korte, ofte tilspissede, komplekser lateralt eller bilateralt med 1-2 sekunders intervaller er tegn på alvorlig skade. Eventuell overlevelse er da som oftest med dårlig nevrologisk restitusjon.

For all komarelatert EEG-patologi er det en grunnregel at manglende reaktivitet ved sensoriske stimuli er et dårlig tegn, med mindre komaen skyldes dyp sedering/narkose (4으). Det er utviklet flere graderingssystemer av EEG-funn for å avhjelpe prognosevurdering. Mest brukt er Syneks gradering, som er enkel og har vist god treffsikkerhet (41) (ramme 1).

\section{RAMME 1}

\section{Syneks gradering av EEG-forandringer ved koma (41)}

Grad 1 Dominerende postsentral alfaaktivitet iblandet tetaaktivitet

Grad 2 Dominerende reaktiv tetaaktivitet

Grad 3 Dominerende omfattende deltaaktivitet eller lavamplitudig uregelmessig og ikkereaktiv deltaaktivitet

Grad 4 «Burst-suppression», generalisert epileptisk aktivitet (herunder status myoclonicus), ikke-reaktiv lavamplitudig aktivitet, alfakoma og tetakoma

Grad 5 Ingen synlig EEG-aktivitet ved registrering med høy sensitivitet

\section{Konklusjon}

EEG kan tidlig gi informasjon om årsak og prognose ved komatilstander. Gjentatte EEGregistreringer øker den diagnostiske sikkerheten og gir mulighet til å følge utviklingen av koma, dels for å vurdere prognose, dels fordi det underveis kan oppstå behandlingstrengende epileptisk aktivitet. Risikoen for utvikling av ikke-konvulsiv status epilepticus er relativt høy ved koma av alle årsaker. Dette understreker betydningen av EEG hos komatøse pasienter. 
EEG har en sentral plass i utredning og behandling av koma

Gjentatte EEG-registreringer kan være nyttig ved koma av alle årsaker

Enkelte årsaker og komplikasjoner ved koma kan kun diagnostiseres ved hjelp av EEG

\section{LITTERATUR}

1. Koehler PJ, Wijdicks EF. Historical study of coma: looking back through medical and neurological texts. Brain 2008; 131: 877-89. [PubMed] [CrossRef]

2. von Economo C. Encephalitis lethargica. Wien Klin Wochenschr 1917;30: 581-5.

3. Moruzzi G, Magoun HW. Brain stem reticular formation and activation of the EEG. Electroencephalogr Clin Neurophysiol 1949; 1: 455-73. [PubMed]

4. Plum F, Posner JB. The diagnosis of stupor and coma. 3. utg. Philadelphia, PA: F.A. Davis, 1980.

5. Young GB. Coma disorders of consciousness. Ann N Y Acad Sci 2009; 1157:32-47. [CrossRef]

6. Buzsaki G, Traub RD, Pedley TA. The cellular basis of EEG activity. I: Ebersole JS, Pedley TA, red. Current practice of clinical electroencephalography. 3. utg. Philadelphia, PA: Lippincott Williams and Wilkins, 2003: 1-11.

7. Ebersole JS. Cortical generators and EEG voltage fields. I: Ebersole JS, Pedley TA, red. Current practice of clinical electroencephalography. 3. utg. Philadelphia, PA: Lippincott Williams and Wilkins, 2003: 12-31.

8. Steriade M, McCormick DA, Sejnowski TJ. Thalamocortical oscillations in the sleeping and aroused brain. Science 1993; 262: 679-85. [PubMed] [CrossRef]

9. McCormick DA. Cortical and subcortical generators of normal and abnormal rhythmicity. Int Rev Neurobiol 2002; 49: 99-114. [PubMed] [CrossRef]

10. Amzica F. In vivo electrophysiological evidences for cortical neuron-glia interactions during slow $(<1 \mathrm{~Hz})$ and paroxysmal sleep oscillations. J Physiol Paris 2002; 96: 209-19. [PubMed] [CrossRef]

11. Kaplan PW. The EEG in metabolic encephalopathy and coma. J Clin Neurophysiol 2004; 21:307-18. [PubMed]

12. Blume WT. Drug effects on EEG. J Clin Neurophysiol 2006; 23:306-11. [PubMed] [CrossRef]

13. Schaul N. Pathogenesis and significance of abnormal nonepileptiform rhythms in the EEG. J Clin Neurophysiol 1990; 7: 229-48. [PubMed] [CrossRef]

14. Schaul N, Gloor P, Gotman J. The EEG in deep midline lesions. Neurology 1981; 31: 157-67. [PubMed] [CrossRef]

15. Schiff N. Central thalamic contributions to arousal regulation and neurological disorders of consciousness. Ann N Y Acad Sci 2008; 1129: 105-18. [CrossRef]

16. McCormick DA, Bal T. Sleep and arousal: thalamocortical mechanisms. Annu Rev Neurosci 1997; 20:185-215. [PubMed] [CrossRef]

17. Young GB, Blume WT, Campbell VM et al. Alpha, theta and alpha-theta coma: a clinical outcome study utilizing serial recordings. Electroencephalogr Clin Neurophysiol 1994; 91: 93-9. [PubMed] [CrossRef]

18. Kaplan PW, Genoud D, Ho TW et al. Etiology, neurologic correlations, and prognosis in alpha coma. Clin Neurophysiol 1999; 110: 205-13. [PubMed] [CrossRef]

19. Gütling E, Isenmann S, Wichmann W. Electrophysiology in the locked-in-syndrome. Neurology 1996; 46: 1092-101. [PubMed] [CrossRef]

20. Bassetti C, Hess CW. Electrophysiology in locked-in syndrome. Neurology 1997; 49:309. [PubMed] [CrossRef]

21. Vargas F, Hilbert G, Gruson D et al. Fulminant Guillain-Barré syndrome mimicking cerebral death: case report and literature review. Intensive Care Med 2000; 26: 623-7. [PubMed] [CrossRef]

22. Drury I. The EEG in hypoxic-ischemic encephalopathy. Am J EEG Technol 1988; 70: 1-8.

23. Brenner RP, Schaul N. Periodic EEG patterns: classification, clinical correlation, and pathophysiology. J Clin Neurophysiol 1990; 7: 249-67. [PubMed] [CrossRef]

24. Young GB, Jordan KG, Doig GS. An assessment of nonconvulsive seizures in the intensive care unit using continuous EEG monitoring: an investigation of variables associated with mortality. Neurology 1996; 47: 83-9. [PubMed] [CrossRef] 
25. Elger CE, Speckmann EJ, Prohaska O et al. Pattern of intracortical potential distribution during focal interictal epileptiform discharges (FIED) and its relation to spinal field potentials in the rat. Electroencephalogr Clin Neurophysiol 1981; 51:393-402. [PubMed] [CrossRef]

26. Amzica F. Basic physiology of burst-suppression. Epilepsia 2009; 50 (suppl 12):38-9. [PubMed] [CrossRef]

27. Brenner RP. Is it status? Epilepsia 2002; 43 (suppl 3): 103-13. [PubMed] [CrossRef]

28. Lowenstein DH, Aminoff MJ. Clinical and EEG features of status epilepticus in comatose patients. Neurology 1992; 42:100-4. [PubMed] [CrossRef]

29. Simon RP, Aminoff MJ. Electrographic status epilepticus in fatal anoxic coma. Ann Neurol 1986; 20:351-5. [PubMed] [CrossRef]

30. Rossetti AO, Oddo M, Liaudet L et al. Predictors of awakening from postanoxic status epilepticus after therapeutic hypothermia. Neurology 2009; 72: 744-9. [PubMed] [CrossRef]

31. Garzon E, Fernandes RM, Sakamoto AC. Serial EEG during human status epilepticus: evidence for PLED as an ictal pattern. Neurology 2001; 57: 1175-83. [PubMed] [CrossRef]

32. Akman CI, Riviello JJ jr. Generalized periodic epileptiform discharges in critically ill children: a continuum of status epilepticus or an epiphenomenon? J Clin Neurophysiol 2011; 28:366-72. [PubMed] [CrossRef]

33. Rossetti AO, Lowenstein DH. Management of refractory status epilepticus in adults: still more questions than answers. Lancet Neurol 2011; 10: 922-30. [PubMed] [CrossRef]

34. Towne AR, Waterhouse EJ, Boggs JG et al. Prevalence of nonconvulsive status epilepticus in comatose patients. Neurology 2000; 54:340-5. [PubMed] [CrossRef]

35. Buchner H, Schuchardt V. Reliability of electroencephalogram in the diagnosis of brain death. Eur Neurol 1990; 30: 138-41. [PubMed] [CrossRef]

36. Chatrian GE. Electrophysiologic evaluation of brain death: A critical appraisal. I: Aminoff MJ, red. Electrodiagnosis in clinical neurology. New York, NY: Churchill Livingstone, 1980: 525-88.

37. Young GB. Ethics in the intensive care unit with emphasis on medical futility in comatose survivors of cardiac arrest. J Clin Neurophysiol 2000; 17: 453-6. [PubMed] [CrossRef]

38. Young GB, Wang JT, Connolly JF. Prognostic determination in anoxic-ischemic and traumatic encephalopathies. JClin Neurophysiol 2004; 21:379-90. [PubMed]

39. Young GB. Clinical practice. Neurologic prognosis after cardiac arrest. N Engl J Med 2009; 361: 605-11. [PubMed] [CrossRef]

40. Logi F, Pasqualetti P, Tomaiuolo F. Predict recovery of consciousness in post-acute severe brain injury: the role of EEG reactivity. Brain Inj 2011; 25: 972-9. [PubMed] [CrossRef]

41. Synek VM. Prognostically important EEG coma patterns in diffuse anoxic and traumatic encephalopathies in adults. J Clin Neurophysiol 1988; 5: 161-74. [PubMed] [CrossRef]

Publisert: 8. januar 2013. Tidsskr Nor Legeforen. DOI:10.4045/tidsskr.11.1432

Mottatt 26.11. 2011, første revisjon innsendt 8.3. 2012, godkjent 21.6. 2012. Medisinsk redaktør Are Brean. (C) Tidsskrift for Den norske legeforening 2023. Lastet ned fra tidsskriftet.no 26. april 2023. 